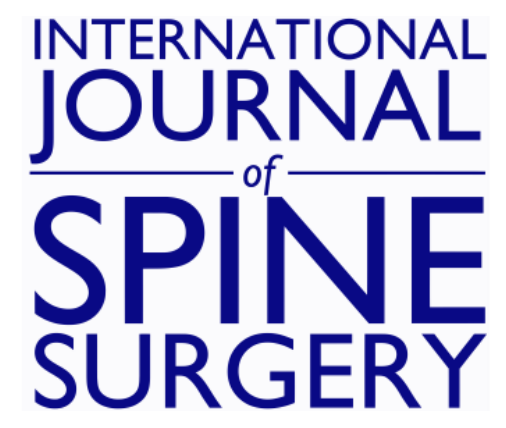

\title{
Clinical and Anatomical Features as well as Pathological Conditions of Surgically Treated Adult Patients with Occipitalization of the Atlas
}

Yasunori Tatara, Takachika Shimizu, Keisuke Fueki, Masatake Ino, Naofumi Toda, Tetsu Tanouchi and Nodoka Manabe

Int J Spine Surg 2016, 10 ()

doi: https://doi.org/10.14444/3005

http://ijssurgery.com/content/10/5

This information is current as of April 26, 2023.

Email Alerts Receive free email-alerts when new articles cite this article. Sign up at:

http://ijssurgery.com/alerts

The International Journal of Sping Surgerthttp://ijssurgery.com/ by guest on April 26, 2 2397 Waterbury Circle, Suite 1,

Aurora, IL 60504, Phone: +1-630-375-1432

(C) 2016 ISASS. All Rights Reserved. 


\section{Clinical and Anatomical Features as well as Pathological Conditions of Surgically Treated Adult Patients with Occipitalization of the Atlas}

Yasunori Tatara, MD,1 Takachika Shimizu, MD, ${ }^{2}$ Keisuke Fueki, MD,2 Masatake Ino, MD, ${ }^{2}$ Naofumi Toda, MD, 2 Tetsu Tanouchi, MD, ${ }^{2}$ Nodoka Manabe, $M D^{2}$

${ }_{1}$ Yokohama Minami Kyosai Hospital, Yokohama, Kanagawa, Japan 2Gunma Spine Center, Harunaso Hospital, Takasaki, Japan

\section{Abstract}

Background

This paper intends to clarify clinical and anatomical features as well as pathological conditions of surgically treated adult patients with occipitalization of the atlas.

\section{Methods}

The authors reviewed 12 consecutive adult patients with occipitalization of the atlas who un-derwent surgery for myleopathy in our hospital. Mainly using preoperative computed tomography and three-dimensional computed tomography angiography, we investigated their anomalies of the osseous structures and vertebral artery at the cervical spine including the craniovertebral junction (CVJ). We also developed a new classification system for occipitalization of the atlas.

Results

Atlantoaxial subluxation (AAS) was detected in 9 patients (75\%). The condition of AAS was irreducible in 7 patients. Among these 7 patients, deformity at the lateral at-lantoaxial joints was detected in 2 patients. C2-3 fusion was detected in 6 patients (67\%) among 9 patients with AAS. Anomalies of the VA were detected in 11 patients (92\%). Occipitalization of the atlas was classified into three types according to their pathological conditions. In type 1 (2 patients) the medial atlantoaxial joint is semi-dislocated and the lateral atlantoaxial joints are severely deformed. Type 2 (7 patients) exhibits AAS but the lateral atlantoaxial joints are not deformed. Type 3 (3 patients) is not associated with AAS and therefore does not exhibit osseous stenosis at the CVJ. In type 3 the myelopathy was caused by another coexisting condition.

\section{Conclusions}

Occipitalization of the atlas is classified into three types. The main pathological condi-tion in both types 1 and 2 is AAS. Reduction of AAS is essential in both; however, reduction of AAS in type 1 is more technically demanding than in type 2 . The pathological conditions of type 3 are completely different from those of the others, so an accurate diagnosis must be made. The new classification system is a useful guide for surgeons when planning surgical strategies.

KEYWORDS: OCCIPITALIZATION OF THE ATLAS, ATLANTOAXIAL SUBLUXATION, CRANIOVERTEBRAL JUNCTION, VERTEBRAL ARTERY VOLUME 9 ARTICLE 5 DOI: 10.14444/3005

\section{Introduction}

Occipitalization of the atlas is defined as congenital fusion of the atlas to the occiput ${ }^{1}$ and the embryologic etiology is explained as follows: first, failure in differentiation of the fused segment consisting of the caudal half of occipital sclerotome 4 and the cranial half of cervical sclerotome 1 , and second, lack of segmentation and separation between the loose and dense zones of cervical sclerotome. ${ }^{1,2,3,4,5}$

Occipitalization of the atlas has been reported to be frequently associated with anomalous vertebral arteries, atlantoaxial subluxation, basilar invagination, cervical vertebral fusions, Chiari malformation, foramen magnum deformities, and platybasia.${ }^{6,7}$ Clinical manifestations of occipitalization of the atlas have been described to vary from neck pain to myelopa- 
thy. ${ }^{6,8,9,10,11,12}$ When patients manifest these symptoms, surgical treatment must depend on their pathological conditions.

The purpose of the current study was twofold: first, to clarify the clinical and anatomical features of surgically treated adult patients with occipitalization of the atlas, mainly using preoperative computed tomography and three-dimensional computed tomography angiography of the cervical spine including the CVJ; second, to develop a new classification system for occipitalization of the atlas in order to clarify their pathological conditions and to consider surgical strategies.

\section{Clinical Materials and Methods}

We analyzed 12 consecutive patients with occipitalization of the atlas who underwent surgery for cervical myelopathy in our hospital between October 2002 and March 2009. The patients were 4 men and 8 women with an average age of 60 years (range, 45-77 years). All patients presented progressive myelopathy. Three patients had comorbidity: Chiari malformation with syringomyelia in one, rheumatoid arthritis (RA) in one, and ossification of the posterior longitudinal ligament (OPLL) in one. All patients underwent preoperative imaging studies as follows: anteroposterior and lateral (neutral, flexion, and extension) radiographs, CT, 3D-CTA, and magnetic resonance imaging of the cervical spine including the CVJ. The follow-up period of patients averaged 100 months (range, 70-147 months).

To clarify the anatomical features of our patients, we investigated their anomalies of the osseous structures and vertebral artery at the CVJ and cervical spine using the preoperative images. The details of the investigation are listed below. We also developed a new classification system for occipitalization of the atlas on the basis of these results in order to explain their pathological conditions and to consider surgical strategies for the patients. The study received institutional review board approval.

Fusion Types of Occipitalization of the Atlas Fusion types of occipitalization of the atlas were defined as a complete fusion type when the anterior at- lantal arch, lateral masses, and posterior arch were fully fused to the occiput on sagittal CT reconstruction images or as a partial fusion type when osseous discontinuity was obvious between the occiput and any segment of the atlas.

Occipital Condyle (in the present study, the occipital condyle in occipitalization of the atlas indicates the fusion segment of the occiput and the lateral mass of the atlas)

The height of both sides of the occipital condyle was measured on coronal CT reconstruction images. When the difference in height between the occipital condyles was more than $3 \mathrm{~mm}$, the morphological difference was judged to be significant. In these cases, the lower side was defined as the hypoplastic side.

\section{Atlantoaxial Joint}

The medial atlantoaxial joint was defined as AAS when an atlantodental interval of more than $4 \mathrm{~mm}$ was observed on lateral radiographs of the cervical spine or sagittal CT reconstruction images. The condition of AAS in each patient was assessed as mobile or irreducible on lateral functional radiographs.

Morphologies of the lateral atlantoaxial joints were carefully observed on sagittal CT reconstruction images. A lateral atlantoaxial joint was defined as severely deformed when the facet of the joint was steepened and the lateral mass of the atlas was displaced anteroinferiorly against the superior facet of the axis.

\section{Vertebral Fusion}

Vertebral fusion was defined either when the fusion of adjacent vertebral bodies was evident or else only when the fusion of adjacent posterior elements was evident.

\section{Vertebral Artery}

The diameter of the VA was measured on 3D-CTA. When the diameter of the VA on one side was smaller than half that of the VA on the other side, the smaller side was defined as the hypoplastic side.

Classically, the VA can be regionally divided into 4 segments. In the present study we mainly discuss the $\mathrm{V} 2$ and the V3 segment of the VA. The V2 segment 
of the VA courses upward through the transverse foramen from $\mathrm{C} 6$ to $\mathrm{C} 2$. The $\mathrm{V} 3$ segment of the VA courses from $\mathrm{C} 2$ to the foramen magnum. ${ }^{13}$

\section{Transverse Foramen}

The diameter of the transverse foramen was measured on axial CT images. When the diameter of the transverse foramen on one side was smaller than half that of the transverse foramen on the other side, the smaller side was defined as the hypoplastic side. The existence of a hypoplastic transverse foramen means that the V2 segment of the VA is anomaly.

\section{Results}

Table 1 shows a summary of osseous anomalies and clinical presentation of 12 patients with occipitalization of the atlas.
Fusion Types of Occipitalization of the Atlas

Complete and partial fusion types were detected in 8 $(67 \%)$ and $4(33 \%)$ patients, respectively. The details of 4 partial fusion type patients were as follows: in case 1 , the anterior atlantal arch was not fused to the occiput, while in case 3 the posterior arch was not fused and the other 2 patients (cases 7 and 10) manifested a posterior hemiarch without fusion to the occiput. The lateral masses in all 12 patients were fused to the occiput.

\section{Occipital Condyle}

Five patients (42\%) demonstrated a hypoplastic occipital condyle on one side (Figure 1). Among these 5 patients, 3 patients were a complete fusion type, and 2 were a partial fusion type.

Table 1. Summary of osseous anomalies and clinical presentation of 12 patients with occipitalization of the atlas.

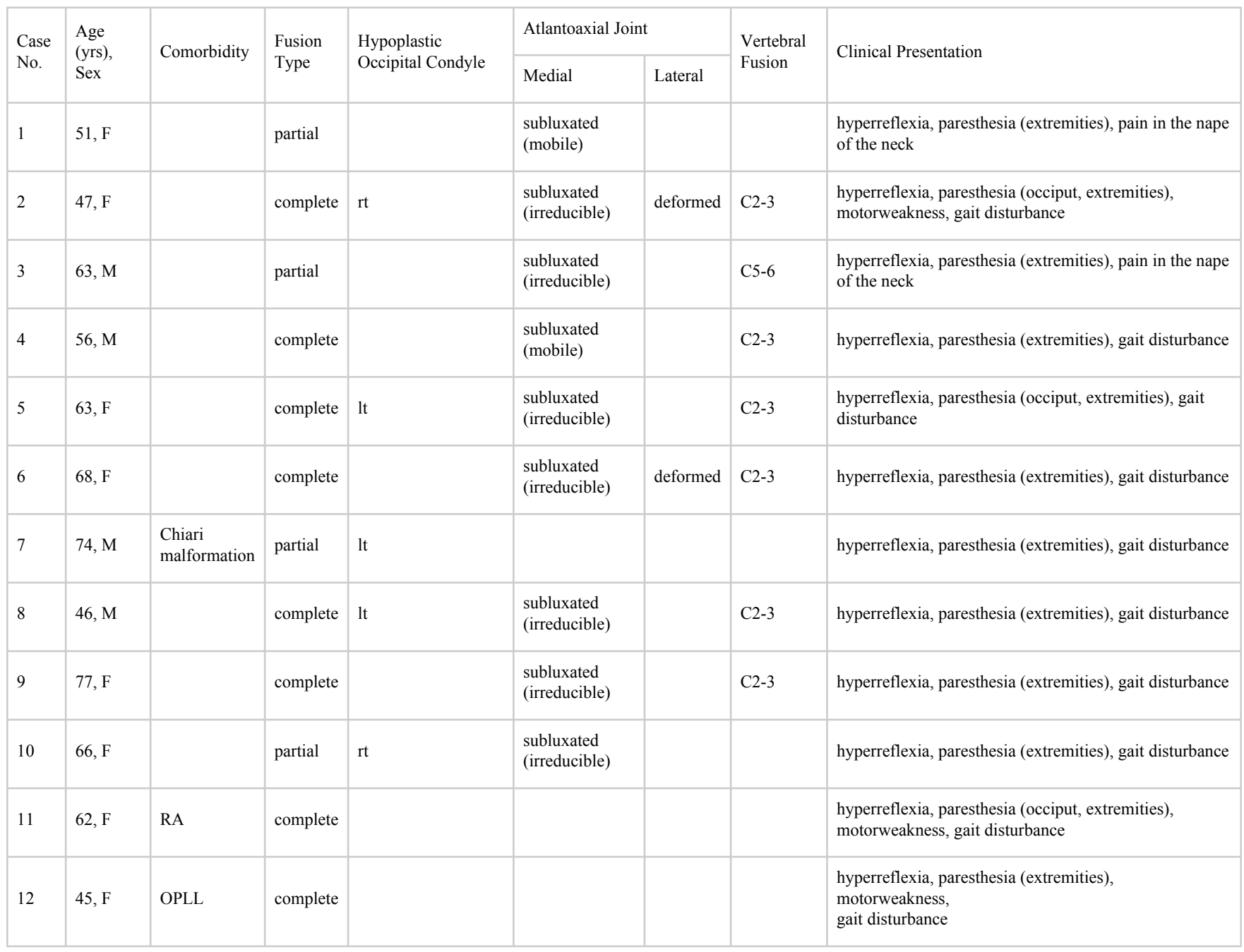

Downloaded from http://ijssurgery.com/ by guest on April 26, 2023 
Atlantoaxial Joint

Nine patients (75\%) manifested AAS. The condition of AAS was mobile in 2 patients and irreducible in 7 patients. Among these 7 patients, 2 patients manifested that the medial atlantoaxial joint was semidislocated and the lateral atlantoaxial joints were severely deformed.

\section{Vertebral Fusion}

Seven patients (58\%) had vertebral fusion. Among these 7 patients, 6 patients had vertebral fusion at C2-3 and 1 at C5-6. Among these 6 patients with C2-3 fusion, 5 patients had the fusion at both the anterior and posterior elements, and the other one at the posterior elements only.

All 6 patients with C2-3 fusion were a complete fusion type and had hypoplastic C2. C2-3 fusion was detected in 6 patients (67\%) among 9 patients with AAS. On the other hand, 1 patient with C5-6 fusion was a partial fusion type and had neither hypoplastic C2, C5 nor C6.

\section{Surgical Methods and Outcomes}

All patients were placed prone with their skulls fixed with a halo ring anchored with a special adaptor to the Mayfield apparatus. All 11 patients except case 7 underwent either occipitocervical or occipitothoracic fusion using an occipitocervical/thoracic loop rod system (RRS loop spine system). If patients were associated with AAS, cervical traction was applied by raising the head end of the table in order to facilitate reduction of AAS. For all 7 patients with irreducible

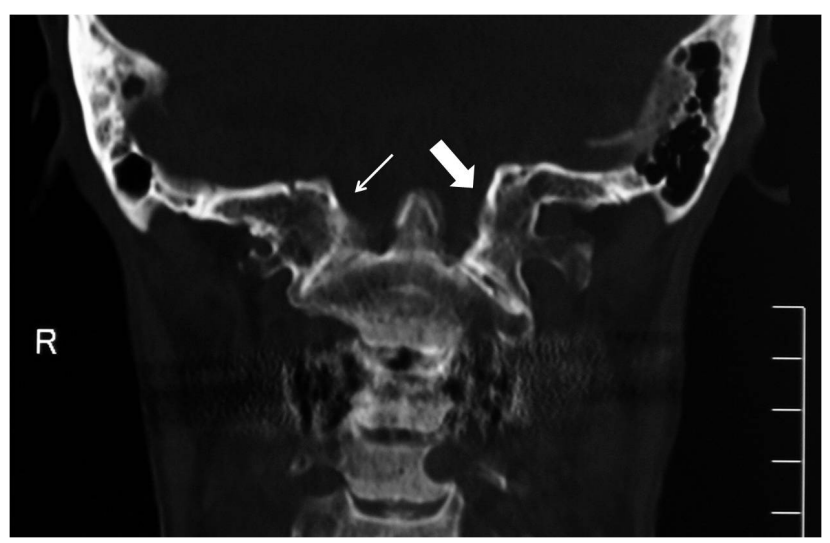

Fig. 1. Coronal CT reconstruction image of the occipital condyle demonstrating that the right occipital condyle (small arrow) is smaller in size than the left occipital condyle (large arrow) and this patient (case 10) manifests torticollis.
AAS, we pushed down on the C2 spinous process toward the anterior atlantal arch under an image intensifier and obtained a satisfactory reduction in 4 patients. The procedure was carefully carried out under spinal cord monitoring.

Both cases 11 and 12 were not associated with AAS. However, both of them underwent the fusion extended to the occiput: case 11 suffered from RA with severe subaxial lesion and case 12 suffered from OPLL extending from the upper cervical to upper thoracic spine as well as associated with torticollis due to anomalies of the CVJ (Table 2).

Neurological symptoms improved to varying degrees in all patients and there were no perioperative complications. A stable bony arthrodesis was achieved in all 11 patients.

Table 2. Summary of surgical methods and outcomes in 12 patients with occipitalization of the atlas.

\begin{tabular}{|c|c|c|c|c|}
\hline \multirow{2}{*}{$\begin{array}{l}\text { Case } \\
\text { No. }\end{array}$} & \multirow{2}{*}{ Surgical Method } & \multicolumn{2}{|l|}{ AAS } & \multirow{2}{*}{ Outcome } \\
\hline & & Preop. & Postop. & \\
\hline 1 & $\begin{array}{l}\text { Occ-C3 PSF and C1 } \\
\text { laminectomy }\end{array}$ & $\begin{array}{l}\text { subluxated } \\
\text { (mobile) }\end{array}$ & reduced & improvement \\
\hline 2 & $\begin{array}{l}\text { Occ-C4 PSF, C1 } \\
\text { laminectomy, and C4-6 } \\
\text { laminoplasty }\end{array}$ & $\begin{array}{l}\text { subluxated } \\
\text { (irreducible) }\end{array}$ & $\begin{array}{l}\text { not } \\
\text { reduced }\end{array}$ & improvement \\
\hline 3 & $\begin{array}{l}\text { Occ-C3 PSF and C1 } \\
\text { laminectomy }\end{array}$ & $\begin{array}{l}\text { subluxated } \\
\text { (irreducible) }\end{array}$ & reduced & improvement \\
\hline 4 & $\begin{array}{l}\text { Occ-C3 PSF, C1 } \\
\text { laminectomy, and C4-6 } \\
\text { laminoplasty }\end{array}$ & $\begin{array}{l}\text { subluxated } \\
\text { (mobile) }\end{array}$ & reduced & improvement \\
\hline 5 & $\begin{array}{l}\text { Occ-C4 PSF and C1 } \\
\text { laminectomy }\end{array}$ & $\begin{array}{l}\text { subluxated } \\
\text { (irreducible) }\end{array}$ & $\begin{array}{l}\text { not } \\
\text { reduced }\end{array}$ & improvement \\
\hline 6 & $\begin{array}{l}\text { Occ-C7 PSF and C1 } \\
\text { laminectomy }\end{array}$ & $\begin{array}{l}\text { subluxated } \\
\text { (irreducible) }\end{array}$ & $\begin{array}{l}\text { not } \\
\text { reduced }\end{array}$ & improvement \\
\hline 7 & $\begin{array}{l}\text { foramen magnum } \\
\text { decompression }\end{array}$ & & & improvement \\
\hline 8 & $\begin{array}{l}\text { Occ-C4 PSF and C1 } \\
\text { laminectomy }\end{array}$ & $\begin{array}{l}\text { subluxated } \\
\text { (irreducible) }\end{array}$ & reduced & improvement \\
\hline 9 & $\begin{array}{l}\text { Occ-C5 PSF and C1 } \\
\text { laminectomy }\end{array}$ & $\begin{array}{l}\text { subluxated } \\
\text { (irreducible) }\end{array}$ & reduced & improvement \\
\hline 10 & $\begin{array}{l}\text { Occ-C7 PSF and C1 } \\
\text { laminectomy }\end{array}$ & $\begin{array}{l}\text { subluxated } \\
\text { (irreducible) }\end{array}$ & reduced & improvement \\
\hline 11 & Occ-T2 PSF & & & improvement \\
\hline 12 & Occ-T3 PSF & & & improvement \\
\hline
\end{tabular}




\section{Vertebral Artery}

Table 3 shows a summary of VA anomalies in 12 patients. Anomalies of the VA were detected in $11 \mathrm{pa}-$ tients (92\%). Among these 11 patients, 9 patients deviated from the normal V3 segment pathway of the VA on one side or both (Figure 2). When the groove for the VA on the atlas was obliterated on one side or both because the posterior atlantal arch was fused to the occiput, in the present study we found two anomalous types of the V3 segment pathway: one type entered the cranium via the extraspinal canal after exiting the transverse foramen of the axis, and the other entered the cranium via the intraspinal canal under the atlas.

Hypoplasia or agenesis of the VA existed in $10 \mathrm{pa}-$ tients (83\%). Among these 10 patients, 5 patients manifested a hypoplastic transverse foramen, that is, an anomalous V2 segment pathway. Among these 5 patients, 4 patients manifested agenesis of the VA on

\begin{tabular}{|c|c|c|c|c|}
\hline Case No. & $\begin{array}{l}\text { Fusion } \\
\text { Type }\end{array}$ & $\begin{array}{l}\text { Morphology } \\
\text { of the VA }\end{array}$ & $\begin{array}{l}\text { Hypoplastic } \\
\text { Side of the } \\
\text { Transverse } \\
\text { Foramen }\end{array}$ & $\begin{array}{l}\text { Course of the V3 } \\
\text { Segment of the VA } \\
\text { into the Cranium }\end{array}$ \\
\hline 1 & partial & $\begin{array}{l}\text { rt, } \\
\text { hypoplasia }\end{array}$ & & $\begin{array}{l}\text { both sides: } \\
\text { extraspinal canal }\end{array}$ \\
\hline 2 & complete & $\begin{array}{l}\text { rt, } \\
\text { hypoplasia }\end{array}$ & & $\begin{array}{l}\text { both sides: } \\
\text { extraspinal canal }\end{array}$ \\
\hline 3 & partial & no laterality & & both sides: normal \\
\hline 4 & complete & rt, agenesis & $\mathrm{rt}$ & $\begin{array}{l}\text { lt: intraspinal canal } \\
\text { under the atlas }\end{array}$ \\
\hline 5 & complete & lt, agenesis & lt & rt: extraspinal canal \\
\hline 6 & complete & $\begin{array}{l}\text { rt, } \\
\text { hypoplasia }\end{array}$ & & $\begin{array}{l}\text { both sides: } \\
\text { extraspinal canal }\end{array}$ \\
\hline 7 & partial & lt, agenesis & lt & rt: normal \\
\hline 8 & complete & no laterality & & $\begin{array}{l}\text { rt: extraspinal canal } \\
\text { lt: intraspinal canal } \\
\text { under the atlas }\end{array}$ \\
\hline 9 & complete & $\begin{array}{l}\text { rt, } \\
\text { hypoplasia }\end{array}$ & & $\begin{array}{l}\text { both sides: } \\
\text { extraspinal canal }\end{array}$ \\
\hline 10 & partial & rt, agenesis & $\mathrm{rt}$ & 1t: normal \\
\hline 11 & complete & $\begin{array}{l}\text { rt, } \\
\text { hypoplasia }\end{array}$ & & $\begin{array}{l}\text { both sides: } \\
\text { extraspinal canal }\end{array}$ \\
\hline 12 & complete & $\begin{array}{l}\text { rt, } \\
\text { hypoplasia }\end{array}$ & $\mathrm{rt}$ & $\begin{array}{l}\text { both sides: } \\
\text { extraspinal canal }\end{array}$ \\
\hline
\end{tabular}

the ipsilateral side and hence agenesis of the VA was involved with an anomalous V2 segment pathway at a high incidence (80\%). In 8 patients $(67 \%)$ the left side of the VA was dominant, in 2 patients the right side, and the remaining 2 had no laterality.

\section{Classification System}

Figure 3 shows a new classification system for occipitalization of the atlas which was developed to clarify pathological conditions and to consider surgical strategies for the patients based on the morphology of the atlantoaxial joints. In type 1 (Figure 4) the medial atlantoaxial joint is semi-dislocated and the lateral atlantoaxial joints are severely deformed; therefore type 1 is morphologically the severest condition and we didn't achieve complete reduction of AAS in all cases (2 and 6). Type 2 (Figure 5) exhibits AAS but the lateral atlantoaxial joints are not severely deformed. Type 2 was the most frequent type in the present study. We achieved complete reduction in 6 of 7 type 2 patients except for case 5 , and among these 6 patients, 4 patients (cases 3, 8, 9, and 10) had been preoperatively assessed as irreducible AAS. Type 3 (Figure 6) is not associated with AAS and therefore does not exhibit osseous stenosis at CVJ. Causative diseases for myelopathy in three type 3 patients were Chiari malformation with syringomyelia, RA with subaxial lesions, and OPLL with torticollis, respectively.

Regarding the relationship between symptoms and types of occipitalization of the atlas, cases 1 and 3 presented pain in the nape of the neck and cases 2 and 11 presented paresthesia in the occiput, but there were no significant differences in the symptoms of

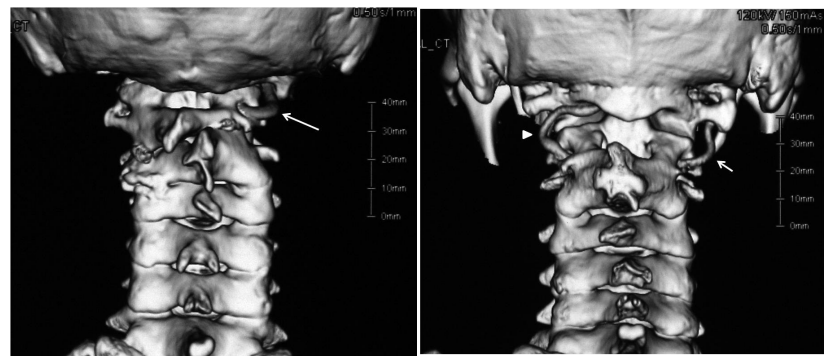

Fig. 2. 3D-CTA reconstruction images demonstrating typical cases of anomalous VAs. Left (case 5): The left VA is agenesis and the right VA enters the cranium via the extraspinal canal after exiting the transverse foramen of the axis. Right (case 8): The left VA (arrow head) enters the cranium via the intraspinal canal under the atlas and the right VA (arrow) enters the cranium via the extraspinal canal. 
the three types of patients.

\section{Discussion}

Several authors ${ }^{14,15,16}$ reported excellent surgical results of patients with occipitalization of the atlas. Besides these reports, we found no detailed reports in English literature on operations for occipitalization of the atlas. The purpose of the current study was twofold; first, to clarify the clinical and anatomical features of surgically treated adult patients with occipitalization of the atlas; second, to develop a new classification system for the occipitalization of the atlas in order to clarify their pathological conditions and to consider surgical strategies.

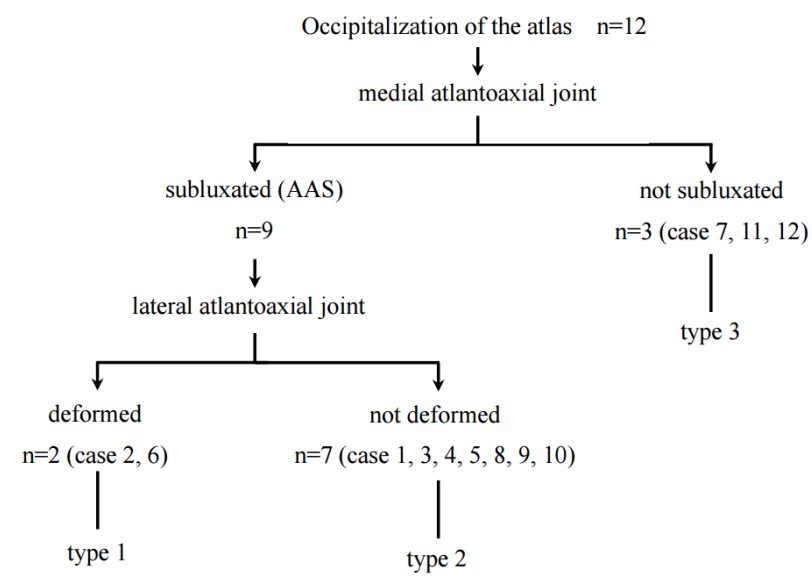

Fig. 3. Flow diagram of the classification for occipitalization of the atlas.

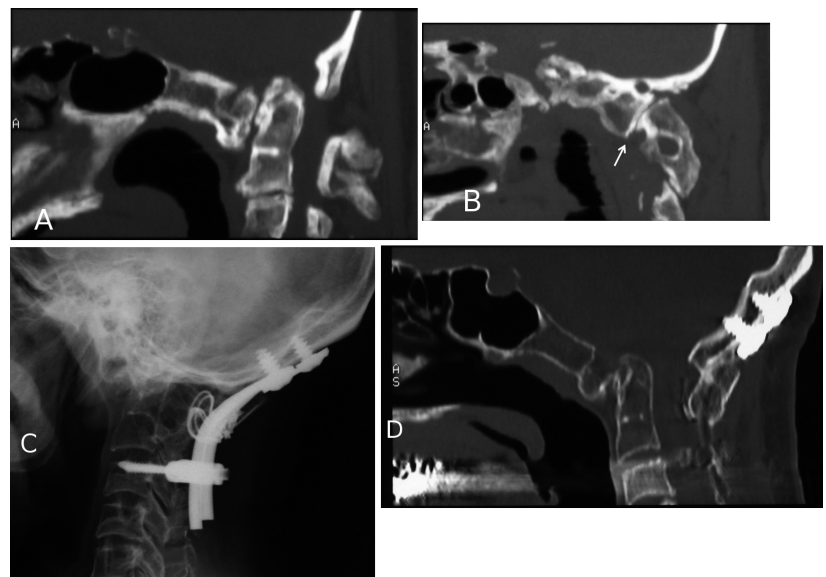

Fig. 4. Type 1 (case 2). Preoperative midsagittal (A) and parasagittal (B) CT reconstruction images demonstrating that the atlas is completely fused with the occiput. The medial atlantoaxial joint is semi-dislocated. The lateral atlantoaxial joint (arrow) is severely deformed and the lateral mass is slipped anteroinferiorly against the superior facet of the axis. Postoperative $x$-ray film (C) and midsagittal CT reconstruction (D) images demonstrating that AAS remains to some degree but a stable bony arthrodesis is obtained.
On the basis of the present study, we classified occipitalization of the atlas into three types mainly according to morphologies of the medial and lateral atlantoaxial joints. We consider that occipitalization of the atlas is accompanied with basilar invagination in a greater or lesser degree. There are 2 reasons: first, fusion of the occiput and atlas causes the distance between the tip of the odontoid and the foramen magnum to be shortened, and second, the occipital condyle in patients with occipitalization of the atlas appears to be hypoplastic compared with the normal occipital condyle. In the present study, complete and partial fusion type patients manifested a hypoplastic occipital condyle in $38 \%$ and $50 \%$ respectively. Although our sample size was small, an isolated basilar invagination does not sufficiently explain the symptoms exhibited by these patients because of the wide canal at the CVJ in general. In both complete and partial fusion types, $75 \%$ of patients exhibited AAS, and all the patients underwent surgery over 45 years of age; therefore, AAS which developed with degeneration was found to be the main pathological condition in myelopathic patients with occipitalization of the atlas. If the myelopathic patients do not manifest AAS, they may have another concurrent disease.
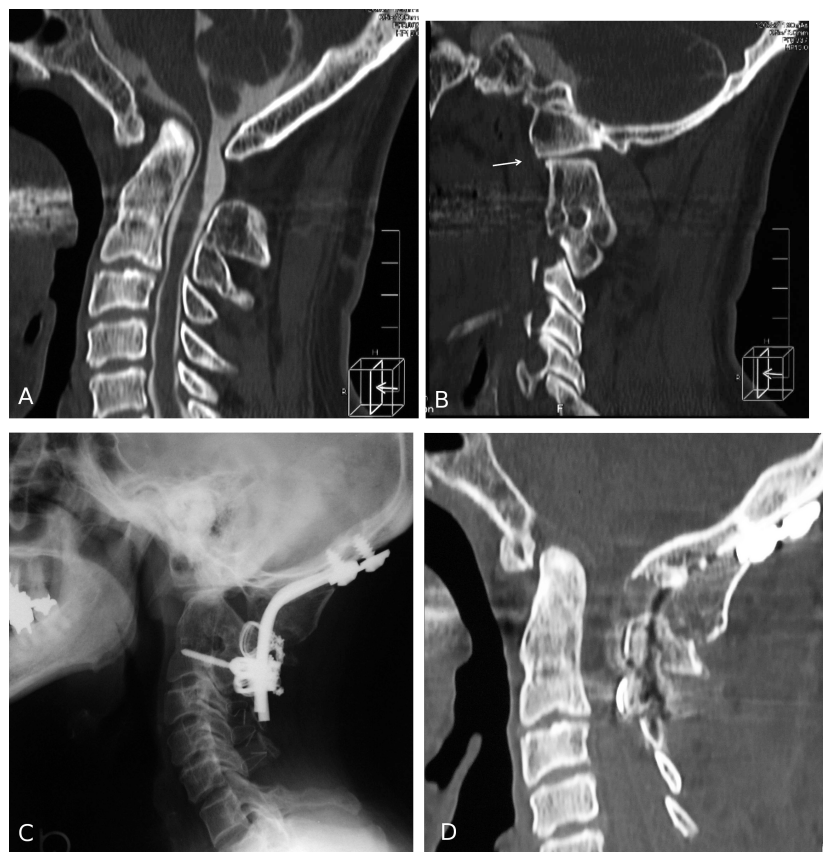

Fig. 5. Type 2. Preoperative midsagittal (A) and parasagittal (B) CT reconstruction images demonstrating that case 4 is a complete fusion type and the lateral atlantoaxial joint (arrow) is slightly loose but almost normal in shape. C2-3 fusion is also demonstrated. Postoperative x-ray film (C) and midsagittal CT reconstruction (D) images demonstrating that AAS is reduced and a stable bony arthrodesis is obtained. 
AAS is the main pathological condition in both types 1 and 2, so that reduction of AAS is an essential strategy. As a prerequisite for this strategy, in general, it is necessary to preoperatively determine whether AAS in each patient is mobile or irreducible. In the present study, we performed posterior occipitocervical fusion alone even when AAS was irreducible and achieved reduction of the preoperatively irreducible AAS in 4 of 7 patients. Therefore, some patients with irreducible AAS could be managed by posterior fusion alone and it is important to know before surgery in which patients with irreducible AAS surgical reduction may be possible. Among 7 irreducible AAS patients, AAS in 3 patients remained postoperatively. Among these 3 patients, 2 patients (type 1) had severely deformed lateral atlantoaxial joints. Based on our morphological study, a severely deformed joint is a big factor which prevents reduction of preoperatively irreducible AAS. Hence, type 2 patients could be managed by posterior occipitocervical fusion alone even when their AAS are irreducible. Yin et al. ${ }^{17}$ described four types of the lateral atlantoaxial joints in congenital anomaly with occipitalization of the atlas. Their cases of type 3 were defined that the superior facet and the inferior facet of lateral atlantoaxial joints were usually located in the vertical direction. They reported that type 3 cases were irreducible atlantoaxial dislocation, so that their type 3 seems consistent with our type 1 . Their types 1,2 , and 4 were moderate deformed joints and seem to be included in our type 2 .
Considering the difference of pathological conditions between types 1 and 2, some surgeons may select transoral decompression ${ }^{18,19,20}$ followed by posterior occipitocervical fusion on type 1 patients. We have actually never experienced transoral surgery for type 1 patients, but achieved neurological improvement to varying degrees in our patients and no perioperative complications occurred. Surgical strategy for type 1 patients remains controversial. With current surgical practices, reduction of type 1 AAS is considered highly technically demanding, possibly next to impossible and there is yet room for further improvement in our surgical strategy for these patients in order to aim for better outcomes.

Type 3 does not demonstrate osseous stenosis at CVJ. The pathological conditions of type 3 are obviously different from those of the others, so that an accurate diagnosis needs to be made.

Among 9 patients with AAS, 6 patients (67\%) manifested C2-3 fusion. Some authors ${ }^{6,8,11,21}$ reported that C2-3 fusion appeared to place additional strain on the atlantoaxial joint during flexion and extension, and that repeated excessive strain at this joint likely predisposed a patient to atlantoaxial instability. On the other hand, AAS in type 1 may be due to congenital factors because the lateral atlantoaxial joints are severely deformed. The etiology of AAS remains uncertain, so patients with C2-3 fusion need following up even if they do not manifest AAS.

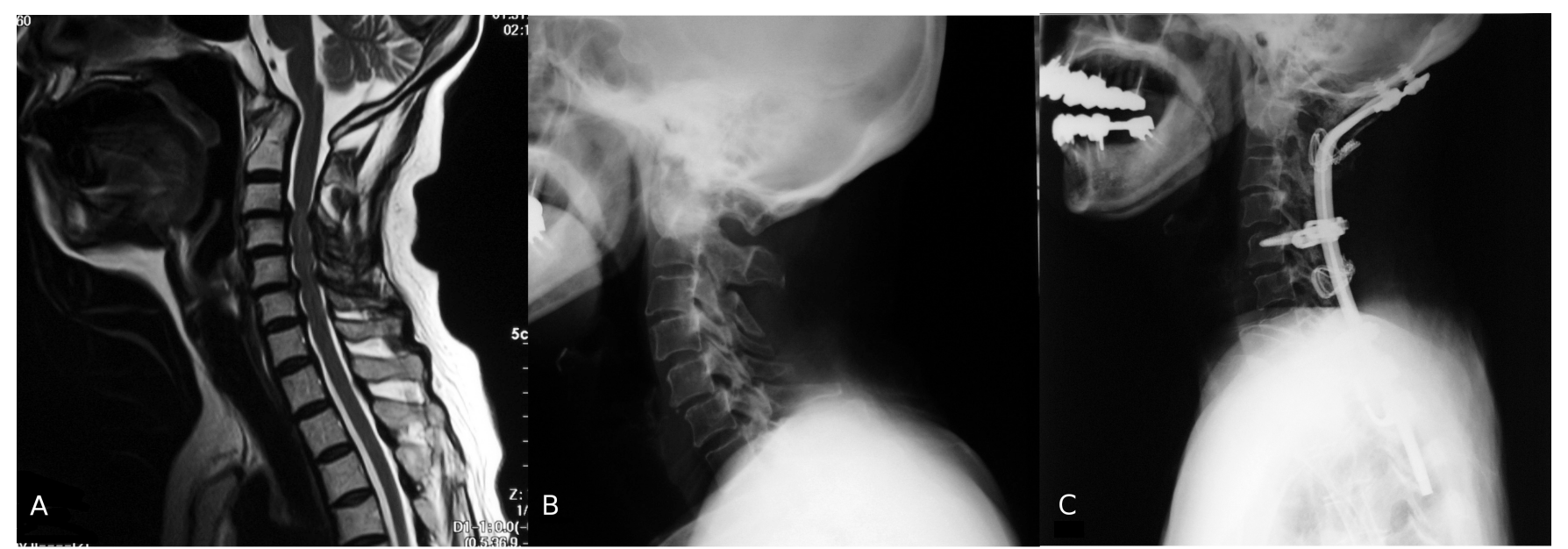

Fig. 6. Type 3. Preoperative sagittal T2-weighted MR image (A) and x-ray film (B) of case 11 associated with rheumatoid arthritis demonstrating subaxial stenosis and subaxial instability but a wide space available for the cord at the CVJ. Postoperative x-ray film (C) demonstrating the cervical spine is successfully realigned and balanced. 
Anomalies of the VA with occipitalization of the atlas may well be due to osseous anomalies at the V2 and/ or V3 segments. In the present study anomalous pathways of the V2 and V3 segments were detected in $42 \%$ and $75 \%$ respectively. Embryologically, the VA is formed from the longitudinal anastomosis of the intersegmental arteries, which does not occur before the resegmentation stage of the CVJ. ${ }^{22}$ Wang et al. ${ }^{13}$ described four types of anomalous VA in their $36 \mathrm{pa}$ tients with occipitalization of the atlas. Although their classification is also applicable to our patients, they did not mention the existence of hypoplastic VAs and V2 segment anomalies such as a hypoplastic transverse foramen.

It is essential for surgeons to understand the precise anatomy of the CVJ and cervical spine in patients with occipitalization of the atlas because their anomalies are easy to lead surgeons to endanger the VA and to be disorientated when approaching and screwing. Surgeons ought not to persist in using only screws but to have another choice such as sublaminar wiring, which is still a useful technique. Surgeons also must pay attention to torticollis because of a high incidence of anomalies such as a hypoplastic occipital condyle and vertebral fusion.

\section{References}

1. Smoker WR. MR imaging of the craniovertebral junction. Magn Reson Imaging Clin N Am. 2000;8(3):635-650.

2. Al-Motabagani MA, Surendra M. Total occipitalization of the atlas. Anat Sci Int. 2006;81(3):173-180.

3. Hosalkar HS, Sankar WN, Wills BP, Goebel J, Dormans JP, Drummond DS. Congenital osseous anomalies of the upper cervical spine. J Bone Jt Surg Am. 2008;90(2):337-348.

4. Muller F, O'Rahilly R. Occipitocervical segmentation in staged human embryos. J Anat. 1994;185 ( Pt 2:251-258.

5. Williams A Collins P NR. Development of the vertebral column. Standring S, ed. Gray's Anat. 2005:798.

6. Gholve PA, Hosalkar HS, Ricchetti ET, Pollock AN, Dormans JP, Drummond DS. Occipitalization of the atlas in children. Morphologic classification, associations, and clinical relevance. J Bone Jt Surg Am. 2007;89(3):571-578.

7. Harcourt BT, Mitchell TC. Occipitalization of the atlas. J Manip Physiol Ther. 1990;13(9):532-538. 8. Bharucha EP, Dastur HM. Craniovertebral Anomalies (a Report on 40 Cases). Brain. 1964;87:469-480.

9. Erbengi A, Oge HK. Congenital malformations of the craniovertebral junction: classification and surgical treatment. Acta Neurochir. 1994;127(3-4):180-185.

10. Guille JT, Sherk HH. Congenital osseous anomalies of the upper and lower cervical spine in children. J Bone Jt Surg Am. 2002;84-A(2):277-288.

11. McRae DL. Bony abnormalities in the region of the foramen magnum: correlation of the anatomic and neurologic findings. Acta radiol.

1953;40(2-3):335-354.

12. McRae DL, Barnum AS. Occipitalization of the atlas. Am J Roentgenol Radium Ther Nucl Med. 1953;70(1):23-46.

13. Wang S, Wang C, Liu Y, Yan M, Zhou H. Anomalous vertebral artery in craniovertebral junction with occipitalization of the atlas. Spine (Phila Pa 1976). 2009;34(26):2838-2842.

14. Yin Y, Yu X, Qiao G, Guo S, Zhang J. C1 lateral mass screw placement in occipitalization with atlantoaxial dislocation and basilar invagination: a report of 146 cases. Spine (Phila Pa 1976). 2014;39(24):2013-2018.

15. Wang S, Wang C, Yan M, Zhou H, Dang G. Novel surgical classification and treatment strategy for atlantoaxial dislocations. Spine (Phila Pa 1976). 2013;38(21):E1348-E1356.

16. Goel A. Treatment of basilar invagination by atlantoaxial joint distraction and direct lateral mass fixation. J Neurosurg Spine. 2004;1(3):281-286.

17. Yin $\mathrm{Y}, \mathrm{Yu} \mathrm{X}, \mathrm{Zhou} \mathrm{D}$, et al. Three-dimensional configuration and morphometric analysis of the lateral atlantoaxial articulation in congenital anomaly with occipitalization of the atlas. Spine (Phila Pa 1976). 2012;37(3):E170-E173.

18. Dickman CA, Locantro J, Fessler RG. The influence of transoral odontoid resection on stability of the craniovertebral junction. J Neurosurg. 1992;77(4):525-530.

19. Goel A, Bhatjiwale M, Desai K. Basilar invagi- 
nation: a study based on 190 surgically treated patients. J Neurosurg. 1998;88(6):962-968.

20. Menezes AH, VanGilder JC. Transoraltranspharyngeal approach to the anterior craniocervical junction. Ten-year experience with 72 patients. J Neurosurg. 1988;69(6):895-903.

21. Hensinger RN. Osseous anomalies of the craniovertebral junction. Spine (Phila Pa 1976). 1986;11(4):323-333.

22. Tokuda K, Miyasaka K, Abe H, et al. Anomalous atlantoaxial portions of vertebral and posterior inferior cerebellar arteries. Neuroradiology.

1985;27(5):410-413.

\section{Disclosures}

The authors declare no relevant disclosures or con- flicts of interest.

\section{Corresponding Author}

Yasunori Tatara, M.D., Spine Center, Yokohama Minami Kyosai Hospital, 1-21-1, Mutsuurahigasi, Kanazawa-ku, Yokohama, Kanagawa, 236-0037, Japan. yata20101107@gmail.com.

Published 21 January 2016.

This manuscript is generously published free of charge by ISASS, the International Society for the Advancement of Spine Surgery. Copyright @ 2016 ISASS. To see more or order reprints or permissions, see http://ijssurgery.com. 